\title{
ОЦЕНКА ВИДОВОГО СОСТАВА МИКОБИОТЬ РАСТЕНИЙ РАЗЛИЧНОГО НАЗНАЧЕНИЯ, РАСПРОСТРАНЕННЫХ В ЗАПАДНОМ РЕГИОНЕ АЗЕРБАЙДЖАНА
}

\section{ASSESSMENT OF MYCOBIOTA OF DIFFERENT TYPES OF PLANTS BY SPECIES COMPOSITION SPREAD IN THE WESTERN REGION OF AZERBAIJAN \\ M. Gasimova \\ N. Hajiyeva \\ F. Bayramova}

Summary. In research was studied mycobiota of about 50 species of cultivated and wild plants by the species composition distributed in the western region of Azerbaijan used for various purposes. It became clear that in the formation of their mycobiota are involved 92 species of true fungi of which $70.4 \%$ of them are belongs to the Ascomycota, $20.2 \%$ to the Bazidiomycota and $9.4 \%$ to the Zygomycota. In addition, fungi such as Cehpalosporium lecanii Zimm. and Gliocladium nigrum Moreau \& V. Moreau were recorded for the first time in the nature of Azerbaijan, and many and many of those recorded belongs to the phytopathogens that cause dangerous diseases in plants.

Keywords: plant, fungi, species composition, phytopathogenic species.
Гасымова Мехпаре Ибрагим кызы

Доктор философии по биологии, и.о. дочент, Азербайджанский Государственный Аграрный

Университет, г. Гянджа qmehpare@mail.ru

Гаджиева Назакат Шамиль кызы

Д.б.н., в.н.С., Институт Микробиологии НАНА, г. Баку nazakat.haciyeva@gmail.com

Байрамова Фериба Васив кызы Докторант, Бакинский Государственный Университет, г. Баку feriba.bayramova1990@mail.ru

Аннотация. В ходе проведенных исследований изучен видовой состав микобиоты около 50 видов культурных и дикорастущих растений, распространенных в западном регионе Азербайджана и используемых для различных целей. Установлено, что в формировании микобиоты этих растений участвуют 92 вида настоящих грибов, из которых 70,4\% - сумчатые грибы (Ascomycota), 20,2\% - базидиомицеты и 9,4\% - зигомицеты (Zygomycota). Кроме того, такие виды, как Cehpalosporium lecanii Zimm и Gliocladium nigrum Moreau \& V. Moreau, впервые зарегистрированы в природе Азербайджана и многие из них принадлежат к фитопатогенам, вызывающим опасные заболевания растений.

Ключевые слова: растение, гриб, видовой состав, фитопатогенные виды.
$\mathbf{H}$ еуклонный рост населения мира ведет к расширению экономической деятельности человека, что сопровождается значительными изменениями существующих природных экосистем[8, 23]. Территории, подверженные глубоким преобразованиям и интенсивно используемые для различных целей, со временем теряют свою устойчивость как экосистемы, а ландшафты деградируют с восходящей тенденцией [16]. В результате этого сокращается биоразнообразие, которое в настоящее время является глобальной экологической проблемой, и анализ литературных данных показывает, что многие виды сейчас находятся под угрозой исчезновения и это число увеличивается с каждым годом [22]. Необходимость устранения такого рода последствий является, без сомнения, одной из актуальных задач.

На фоне задач, поставленных исследованиями в этом направлении, охрана биоразнообразия, улучшение экологической ситуации, эффективное использование природных ресурсов, обеспечение населения планеты продуктами питания и т.д. находятся в центре особого внимания. Так, продукты растительного происхождения имеют особое значение как с точки зрения объема, так и с точки зрения функциональной ценности. Поэтому, В связи с обеспечением населения такой продукцией созданы высокоурожайные сорта растений, а получение из них целевой продукции рассматривается в настоящее время как серьезный результат в направлении устранения материального дефицита. Однако, часть ежегодно получаемой продукции теряется ввиду различных причин, среди которых важное место занимают болезни, вызываемые различными организмами, в первую очередь, грибами $[15,18]$. Так, при эфитотии болезни, вызванной тем или иным грибом, потери урожая могут достигать 50\%, а иногда и больше [3-5], а ежегодные потери урожая от грибковых заболеваний измеряются миллионами тонн. Неслучайно предотвращение этого является во всем мире одной из актуальных задач различных областей наук, в первую очередь, биологических и аграрных. 
Важная роль аграрного сектора в экономике Азербайджанской Республики, широкое возделывание продовольственных и кормовых культур $[1,10]$ позволяют отметить, что эти вопросы являются не новыми и для нашей страны. Так, богатство природы, разнообразие природно-климатических условий привели к распространению в Азербайджане ряда болезнетворных грибов, и их изучению посвящено множество исследований. Большая часть проведенных исследований сосредоточена на изучении патогенных грибов, вызывающих заболевания у культурных растений [6-7, 9, 14]. Хотя исследования по изучению микобиоты у дикорастущих растений ведутся давно, результаты проведенных до сих пор исследований не позволяют обобщить микобиоту не только широко распространенных в Азербайджане дикорастущих растений, но и конкретных видов.

Поэтому целью данной работы была оценка видового состава микобиоты некоторых растений, дикорастущих или культивируемых в Азербайджане.

\section{Материалы и метолы}

Исследование проводилось в Гянджа-Газахском экономическом районе, и в качестве объекта исследования были выбраны некоторые растения, произрастающие или культивируемые на различных территориях, и обитающие на этих растениях грибы. Следует отметить, что отобранные растения отличаются друг от друга как жизненными формами (деревья, кустарники и травы), так и целями, для которых они используются в настоящее время (еда, корм, красители, лекарства и т.д.).

С этой целью за 2015-2020 гг. были взяты образцы вегетативных и генеративных органов некоторых растений, произрастающих в разных частях исследуемой территории, и на которых предположительно, присутствовали грибы. Отбор образцов проводился согласно методу планового маршрута, широко используемым при микологических исследованиях в работе различных исследователей, и выбором участка для стационарных наблюдений и др. методами. Отбор проб проводился также по сезонам. В целом в ходе исследований было отобрано более 750 проб от 30 видов растений, которые согласно цели исследования анализировались известными методами [12].

Для получения чистых культур грибов, населяющих исследуемые растения, в качестве питательных сред использовали сусло-агар (СА), рисовый агар (РА), крахмальный (КА) и картофельный агар (КА), агаризованные среды Чапека и Чапека-Докса. Приготовление сред, их стерилизацию и розлив в чашки Петри проводили согласно известным методикам [12].
Идентификация грибов проводилась с использованием определителей $[13,21]$, позволяющих оценивать культурально-морфологические и биологические признаки, а также базы данных MMA [20]. Для установления названия грибов использовались материалы с сайта http: www.indexfungorum.org.

\section{Полученные результаты}

и их обсу жАения

Как известно, грибы - стабильные компоненты гетеротрофного блока любой экосистемы, представленные многочисленными видами. Они различаются не только количеством видов, но и разнообразием выполняемых ими функций $[2,11,17]$. Поэтому для выяснения процессов, происходящих в любой экосистеме, важно провести всестороннее исследование распространенных там грибов, которое начинается с видовой характеристики грибов конкретной экосистемы. С этой целью было сочтено целесообразным провести исследование видового состава грибов, распространенных приблизительно на 50 видах растений района исследования (Beta vulgaris L., Cydonia Mill, Fagus orientalis L., Cannabis sativa L., Cornus mas L., Corylus avellana L., Crataegs pentagyna L., Daucus carota L., Helianthus annuus L., Hypericum perforatum L., Juglans regia L., Quercus longipes Stev., Lawsonia inermis L., Linium usitalissimum L., Malus Mill, Glycyrrhiza glabra L., Matricaria chamomilla L., Morus alba L., M.nigra L., Peganum harmala L., Populus L., Rubia tincorum L., Punica granatum L., Robinia pseudoacacia L., Rosa damascena Mill., Sambucus nigra L., Sophora japonica L. и др.).

В ходе исследований, в результате анализа образцов, взятых с некоторых растений, распространенных в западном регионе Азербайджана, выявлено, что в формировании их микобиоты участвуют 92 вида грибов (табл. 1). Как видно, все зарегистрированные грибы принадлежат к истинным грибам (Mycota), так большинство из них - 72,9\% принадлежат к отделу Ascomycota, 7,4\% - Zygomycota, а остальные - 19,7\% относится к отделу Bazidiomycota. Подавляющее большинство грибов, а точнее более $90 \%$, относятся к анаморфам.

Следует отметить, что в большинстве проведенных в Азербайджане микологических исследованиях неоднократно подтверждалось преобладание анаморфных грибов (отмеченные в этих работах как неопределенные грибы). Например, как минимум половина грибов, выявленных в ходе исследований в других частях Азербайджанской Республики, была отнесена к этой группе.

При характеристике количества зарегистрированных грибов установлено, что роды Ascochyta, Aspergillus, 
Таблица 1. Таксономическая структура грибов, зарегистрированных на растениях западного региона Азербайджанской Республики

\begin{tabular}{|c|c|c|c|c|}
\hline Отдел & Класс & Порядок & Семейство & Роды (число видов) \\
\hline Zyqomycota & Mucoromycotina & Mucorales & Mucoraceae & Absidia(1), Mucor(4), Rhizopus(2), \\
\hline \multirow{15}{*}{ Ascomycota } & \multirow{2}{*}{ Leotiomycetes } & Helotiales & Sclerotiniaceae & Monilia(1), Botrytis(1), Sclerotinia(1) \\
\hline & & Erysiphales & Erysiphaceae & Erysiphe(1), Podosphaera(1), Sphaerotheca(1) \\
\hline & Eurotiomycetes & Eurotiales & Trichocomaceae & Aspergillus(5), Penicillium(9) \\
\hline & Taphrinomycetes & Taphrinales(1) & Taphrinaceae(1) & Taphrina(1) \\
\hline & \multirow{6}{*}{ Sordariomycetes } & \multirow[b]{2}{*}{ Hypocreales } & Nectriaceae & Fusarium(6), Nectria(1) \\
\hline & & & Hypocreaceae & $\begin{array}{l}\text { Trichoderma(3), Trichothecium(1), } \\
\text { Cephalosporium(1) }\end{array}$ \\
\hline & & \multirow{3}{*}{ Sordariomycetidae } & Glomerellaceae & Colletotrichum(4) \\
\hline & & & Plectosphaerellaceae & Verticillium(3) \\
\hline & & & Diaporthaceae & Phomopsis(1) \\
\hline & & Microascales & Ceratocystidaceae & Thielaviopsis(1) \\
\hline & \multirow{5}{*}{ Dothideomycetes } & \multirow{2}{*}{ Capnodiales } & Davidiellaceae & Cladosporium(3) \\
\hline & & & Mycosphaerellaceae & Septoria(5) \\
\hline & & Pleosporales & Pleosporaceae & Ascochyta(5), Phoma(3), Alternaria(4), \\
\hline & & Botryosphaeriales & Botryosphaeriaceae & Phyllosticta(3) \\
\hline & & Mytilinidiales & Mytilinidiaceae & Hormiscium(1) \\
\hline \multirow{3}{*}{$\begin{array}{l}\text { Bazidio- } \\
\text { mycota }\end{array}$} & Pucciniomycetes & Pucciniales & Puccinasea & Puccinia(4), Uromyces(3), Gymnosporangium(1) \\
\hline & Ustilaginomycetes & Urocystidales & Urocystidaceae & Urocystis(2) \\
\hline & & & & $\begin{array}{l}\text { Trametes(2), Ganoderma(2) Fomes(1), Phelinus(2), } \\
\text { Inonotus(2) }\end{array}$ \\
\hline
\end{tabular}

Fusarium, Penicillium и Septoria представлены большим количеством

видов, количество которых колеблется от 5 до 9, и 34,6\% от общего количества зарегистрированных грибов относятся к этим родам.

Роды Alternaria, Cladosporium, Colletotrichum, Mucor, Phoma, Phyllosticta, Puccinia, Trichoderma, Verticillium и Uromyces представлены 3-4 (40,7\%) видами, остальные (Absidia, Erysiphe, Rhizobus, Monilia, Botrytis, Phomopsomis, Phomopsomis, Phomopsomis, Trametes, Tafrina, Ganoderma, Fomes, Phellinus и Sclerotinia) представлены 1-2 (24,7\%) видами.

Следует отметить, что сравнивая результаты с результатами микологических исследований, проведенных до сих пор в Азербайджане, становится ясно, что распространение некоторых грибов в природе Азербайджана не выявлено, а количество таких грибов равно 2 (Cehpalosporium lecanii Zimm., Gliocladium nigrum Moreau \& V. Moreau), что составляет 2,5\% от общего числа зарегистрированных грибов. Этот факт, то есть выявление распространения на некоторых растениях западного региона Азербайджана новых видов для микобиоты Азербайджана, четко подтверждает, что эта цифра составляет определенную часть микоразнообразия дан- ной территории. Так, для исследований были отобраны образцы около 50 культурных и дикорастущих растений. Если учесть, что количество растений, распространенных на территории Гянджа-Газахского экономического района во много раз больше, то одним из моментов, на который следует обратить внимание при будущих микологических исследованиях в этих районах, должно стать изучение микобиоты других растений.

Также было бы уместно упомянуть один момент, связанный с формой взаимоотношений грибов с субстратами, то есть с растениями, на которых они обитают. Так, большинство зарегистрированных грибов относятся к политрофам (факультативным), а удельный вес как сапротрофов, так и биотрофов среди них не столь велик. Что касается фитопатогенов, то результаты показали, что среди зарегистрированных грибов были Fusarium moniliforme F.oxysporium, Taphrina deformans Fckl, Podosphaera leucotricha Salm, Puccinia (4), Uromyces (3), Gymnosporangium Alternaria, Sclerotini. Бapbl. Colletotrichum Verticillium Botrytis (1), Erysiphe et al., а в результате вызываемых ими патологий в растениях наблюдаются как физико-химические, так и биологические изменения, в основном, негативного характера. Принятие профилактических мер, направленных на устранение этого явления, представляет собой одно из актуальных направлений современных исследований. 
Таким образом, в ходе проведенных исследований западного региона Азербайджанской Республики, а точнее на территории Гянджа-Газахского экономического района, в образцах около 50 культурных и дикорастущих видов растений выявлено распространение 92 ви- дов грибов. В формировании микобиоты растений обнаруженные грибы участвуют в количестве 1-9 видов, среди которых виды Cehpalosporium lecanii Zimmи Gliocladium nigrum Moreau \& V. Moreau впервые зарегистрированы в природе Азербайджана.

\section{ЛИТЕРАТУРА}

1. Азербайджанская Национальная Энциклопедия. В 25 томах. Азербайджанский том. Баку: Научный центр «Азербайджанская Национальная Энциклопедия", 2007, 884c.

2. Артамонова В.С., Андроханов В. А., Соколов В. А., Лютых И. В. и др. Эколого-физиологическое разнообразие микробных сообществ в техногенно-нарушенных ландшафтах Кузбасса.// Сибирский экологический журнал, 2011, № 5, с. 735-746.

3. Атлас экономически значимых растений и вредных объектов России и сопредельных государств.// http://www.agroatlas.ru/diseases

4. Багирова С.Ф., Джавахия В. Г., Дяков Ю. Т., Озерецковская 0. Л. и др. Фундаментальная фитопатология.М.: Издательство «КРАСАНД», 2012,512 с.

5. Благовещенская Е. Ю. Фитопатогенные микромицеты: Учебный определитель. М.: Ленанд, 2015, 240 c.

6. Гаджиева Н.Ш., Бахшалиева К. Ф., Намазов Н. Р., Гахраманова Ф. Х., Мурадов П. З. Грибы на эфиромасличных растениях, входящих во флору Азербайджана.// Вестник МГОУ, серия «Естественные науки», 2012, № 2, с. 24-27

7. Гаджиева Н.Ш., Мамедов Г. М., Эюбов Б. Б., Мамедова Ф. Р., Гахраманова Ф.Х., Джабраилзаде С. М. Патогенные грибы, обитающие на растениях, культурно возделываемых в условиях Азербайджана.// Вестник МГОУ, серия «Естественные науки», 2012, № 5, с. 9-12

8. Горбатов В.С., Матвеев Ю. М., Кононова Т. В. Экологическая оценка пестицидов: источники и формы информации.//АГРОХ XI, 2008, № 1-3, с. 7-9

9. Мамедова Ф. Р. Роль в в процессе патогенеза гидролитических ферментов некоторых фитопатогенных грибов, распространенных на Апшероне. Автореферат дис.д.ф.п.б.. Баку, 2014, 23с.

10. Мамедов Г. Земельная реформа в Азербайджане: правовые и научно-экологические вопросы. Баку, Элм; 2000, 374с.

11. Марфенина 0. Е. Антропогенная экология почвенных грибов. М.: Медицина для всех, 2005, 195 с.

12. Методы экспериментальной микологии. /под ред. Билай В.И.—Киев: — Наукова думка, — 1982, — 500с.

13. Саттон Д. Определитель патогенных и условно-патогенных грибов / Д. Саттон, А. Фотергилл, М. Ринальди. М.: Мир, 2001.— 486 с..

14. Шихлинский Х. М. Типы фитопатогенных грибов, выделенных из корней винограда, инфицированных филоксерой .// Аграрная Наука Азербайджана, 2004, № 4-6, c. 132-134.

15. Archana J., Surendra S., Qin W., Yuanfu L.\& Jingshan Sh. A review of plant leaf fungal diseases and its environment speciation.// Bioengineered, 2019, 10,1:409-424

16. Avelino, F., and J. Rotmans. 2011. A dynamic conceptualization of power for sustainability research. Journal of Cleaner Production 19:796-804

17. Bardgett R. D. The biology of soil. A Community and Ecosystem Approach. Oxford. 2005, 901 p.

18. Doehlemann G., Ökmen B., Zhu W., Sharon A. Plant Pathogenic Fungi. Microbiol Spectr., 2017, 5(1). doi: 10.1128/microbiolspec.FUNK-0023-2016.

19. Henrique Miguel Pereira, Laetitia Marie Navarro, and Ines Santos Martins. Global Biodiversity Change: The Bad, the Good, and the Unknown Annu.// Rev. Environ. Resour., 2012, v.37, p.25-50

20. https://www.mycobank.org/

21. Kirk P. M., Cannon P. F., Minter D. W. Stalpers J. A. Dictionary of the fungi, 10th edn. CABI publishing. Wallingford (UK), 2008, 600p.

22. Nunez, S., Arets, E., Alkemade, R. et al. Assessing the impacts of climate change on biodiversity: is below $2^{\circ} \mathrm{C}$ enough?.// Climatic Change, 2019, v. 154, p.351-365

23. Van Bavel J. The world population explosion: causes, backgrounds and -projections for the future.//Facts Views Vis Obgyn. 2013, p.5(4), p.281-291.

(c) Гасымова Мехпаре Ибрагим кызы ( qmehpare@mail.ru ),

Гаджиева Назакат Шамиль кызы ( Байрамова Фериба Васив кызы ), Байрамова Фериба Васив кызы ( feriba.bayramova1990@mail.ru ).

Журнал «Современная наука: актуальные проблемы теории и практики» 